\title{
APPROXIMATION BY INTERPOLATION: THE CHEBYSHEV NODES
}

\author{
Mama Foupouagnigni, Daniel Duviol Tcheutia, \\ WOLFRAM KoEPF* AND KingSLEy NJEM ForWA
}

Abstract. In this paper, we first revisit the well-known result stating that the Hermite interpolation polynomials of a function $f$ continuous on $[-1,1]$, with the zeros of the Chebyshev polynomials of the first kind as nodes, converge uniformly to $f$ on $[-1,1]$. Then we extend this result to obtain the uniform convergence of the Hermite interpolation polynomials, with the nodes taken as the zeros of the Chebyshev polynomials of the second, third and fourth kind, not on the interval $[-1,1]$ but rather on the intervals $\left[-\frac{2 \sqrt{2}}{3}, \frac{2 \sqrt{2}}{3}\right],\left[-\frac{\sqrt{3}}{2}, 1\right],\left[-1, \frac{\sqrt{3}}{2}\right]$, respectively.

Mathematics subject classification (2010): 32E30, 97N50.

Keywords and phrases: Hermite Interpolation, approximation, Chebyshev polynomials.

\section{REFERENCES}

[1] K. E. AtKinson, An introduction to numerical analysis, John Wiley \& Sons, second edition (2008).

[2] P. J. DAVIS, Interpolation and approximation, Courier Corporation (1975).

[3] L. FEJÉR, Über Interpolation, Gött. Nachr. (1916) 66-91.

[4] L. Fox And I. Parker, Chebyshev Polynomials in Numerical Analysis, Oxford Univ. Press, Oxford, England (1968).

[5] R. Gervais, Q. I. Rahman And G. Schmeisser, Simultaneous interpolation and approximation by entire functions of exponential type, In: Collatz L., Meinardus G., Werner H. (eds), Numerische Methoden der Approximationstheorie. ISNM International Series of Numerical Mathematics / Internationale Schriftenreihe zur Numerischen Mathematik / Série Internationale D'Analyse Numérique, vol 42. Birkhäuser, Basel (1978) 145-153.

[6] D. LEVY, Introduction to numerical analysis, Department of Mathematics and Center for Scientific Computation and Mathematical Modeling, CSCAMM, University of Maryland (2010).

[7] J. C. MASOn AND D. C. HAndscomb, Chebyshev polynomials, Chapman \& Hall/CRC (2003).

[8] G. Mastroianni And G. Milovanović, Interpolation processes: Basic theory and applications, Springer-Verlag, Berlin Heidelberg (2008).

[9] G. Muntingh, Topics in polynomial interpolation theory, (2011).

[10] G. M. PhILLIPS, Interpolation and approximation by polynomials, volume 14, Springer Science \& Business Media (2003).

[11] A. PInkus, Weierstrass and approximation theory, J. Approx. Theory, 107 (2000) 1-66.

[12] T. Rivlin, The Chebyshev Polynomials, Wiley, New York (1974).

[13] G. SzEgö, Orthogonal polynomials, American Mathematical Society, fourth edition (1975). 